\title{
AN ANALYSIS OF SURGICAL SITE INFECTION IN CLEAN GENERAL SURGICAL OPERATIONS IN PO WARDS
}

\author{
Shantha Kumar Kuzhanthaivelu ${ }^{1}$
}

${ }_{1}^{1}$ Associate Professor, Department of General Surgery, Chengalpattu Government Medical College and Hospital.

ABSTRACT

\section{BACKGROUND}

Surgical site infections represent a significant burden in terms of patient morbidity and mortality and cost to health services around the world. ${ }^{1}$ Surgical site infection (SSI) is a potentially preventable complication. Hence, an observational study was done to determine possible modifiable risk factors, incidence rates and clinical patterns of surgical site infections (SSI) in our institution.

\section{MATERIALS AND METHODS}

This is an observational study on 650 patients who underwent various clean General Surgical operations from 01/01/2008 to $30 / 09 / 2009$, who were analysed from $1^{\text {st }}$ post-operative day to the day of suture removal for SSI in the post-operative wards. Study standards such as pre-operative shower, preoperative antibiotics, operating room environment, operating time for a particular surgery, post-op wound care and other sterility techniques were set similar for all patients who underwent the surgeries.

The statistical significance of the risk factors studied is done by $\mathrm{X}^{2}$ test and the strength of association is determined by Odds Ratio.

\section{RESULTS}

The incidence rate of SSI was $6.2 \%$, which is close to the acceptable rate $(1 \%-5 \%)$ for clean surgeries. Diabetes, anaemia, obesity and duration of surgery have a statistically significant correlation with the development of surgical site infections with odds ratio of each being 19.20, 7.33, 4.75 and 3.14 respectively. Increase in number of risk factors probably further increases the chance of SSI. Staphylococcus aureus was the commonest organism isolated; $76.2 \%$ were due to Gram positive organisms and rest $23.8 \%$ due to Gram negative organisms.

\section{CONCLUSION}

The incidence rate of SSI was within the acceptable limit for all clean surgeries. The strength of association of risk factors studieddiabetes, anaemia, obesity and duration of surgery is well established with the development of SSI. Increase in number of risk factors further compounds the chance of SSI. Staphylococcus aureus was the commonest organism isolated.

\section{KEYWORDS}

SSI (Surgical Site Infections), Clean Surgery, Post-Operative Wound Care.

HOW TO CITE THIS ARTICLE: Kuzhanthaivelu SK. An analysis of surgical site infection in clean general surgical operations in PO wards. J. Evolution Med. Dent. Sci. 2017;6(94):6854-6857, DOI: 10.14260/jemds/2017/1485

\section{BACKGROUND}

Surgical site infections are a real risk associated with any surgical procedure and represent a significant burden in terms of patient morbidity and mortality and cost to health services around the world. Surgical site infections are the most common nosocomial infections in our population and constitute $38 \%$ of all infections in surgical patients. The present generation of surgeons has seen increasing numbers of serious infections related to complex combination of factors including the performance of more complicated and longer operations. Hence, the modern surgeons cannot escape the responsibility of treating surgical site infections.

During the second half of the $19^{\text {th }}$ century, many operations were developed after anaesthesia was introduced by Morton in 1846. But advances in surgeries were few for

'Financial or Other Competing Interest': None.

Submission 21-08-2017, Peer Review 29-11-2017,

Acceptance 05-12-2017, Published 18-12-2017.

Corresponding Author:

Dr. Shantha Kumar Kuzhanthaivelu,

Associate Professor,

Department of General Surgery,

Chengalpattu Government Medical College and Hospital.

E-mail: drkskumarmmc@gmail.com

DOI: $10.14260 /$ jemds/2017/1485

\section{(c) (i) $($ )}

century, Joseph Lister introduced antisepsis into medical practice which reduced infection rates and mortality in surgical patients. The work of Holmes, Pasteur as well as the operating room (OR) environment and discipline established by Hallstead proved that the aseptic and antiseptic techniques are first effective measure for preventing SSI. ${ }^{2}$ With the introduction of antibiotic therapy in the middle of $20^{\text {th }}$ century, a new adjunctive method to treat and prevent SSI was discovered.

\section{Aim of the Study}

The aim of the study was to identify the incidence rates, clinical patterns and outcomes of SSI and to analyse the possible association of various risk factors ${ }^{3}$ (age, diabetes, anaemia, obesity (BMI > 30), duration of surgery) with SSI in clean General Surgical operations in the post-operative wards.

\section{MATERIALS AND METHODS}

This observational study was conducted at Chengalpattu Medical College during the period from 01/01/2008 to $30 / 09 / 2009$. The study was approved by the Institutional Ethical Committee of Chengalpattu Medical College. The study was not sponsored by any agency. Various clean surgical operations were done on 650 patients in the post-operative 
wards. They were included in the study and were analysed for incidence of SSI. Study standards such as pre-operative shower, preoperative antibiotics, operating room environment, operating time for a particular surgery, post-op wound care and other sterility techniques were set similar for all patients who underwent the surgeries.

The demographic data of the patients were collected by the treating surgical team. Other data including associated risks factors (i.e. diabetes, obesity, steroid therapy, etc.), use of prophylactic antimicrobial agents, the type and duration of surgery, clinical evaluation of wound (considered infected if there was pus discharge or redness and swelling with fever), and laboratory data (including gram stain, culture results, identification of the bacterial isolates as well as antimicrobial susceptibility) were recorded on a data sheet and analysed using simple descriptive statistics. Patients were monitored from $1^{\text {st }}$ post-operative day-to-day of suture removal. For those patients developing SSI, pus c/s was done and appropriate antibiotics were given.

The microbiology of SSI was related to the bacterial flora present in the exposed anatomic area after a particular procedure and has been relatively fixed during the past 30 years as shown by the National Nosocomial Infection Surveillance System (NNIS) established by the Centres for Disease Control and Prevention (CDC). ${ }^{4}$

SSIs were diagnosed according to the guidelines of the Centres for Disease Control and Prevention. An operation was defined as any procedure involving skin incision undertaken in an operating theatre under any type of anaesthesia. The operations were classified as clean, clean contaminated, contaminated and dirty according to the system employed in the American College of Surgeons, Committee for Centres of Surgical Infection Qualities.

Swabs from deep part of the wound or pus were taken from the infected surgical sites and routinely from the surface of non-infected ones. The specimens were gram stained and examined for the presence of organisms and pus and cultured aerobically, anaerobically on blood agar as well as in cooked meat broth. Bacterial isolates were identified and tested for antimicrobial susceptibility.

For statistical analyses, the SPSS version is 16.0 and chisquare test was used to analyse the data.

\section{RESULTS}

In this study of 650 cases of clean general surgeries, 41 cases (6.2\%) developed surgical site infection. All the 41 cases had appropriate no. of sutures removed to drain the pus and pus c/s was done for all the cases and appropriate antibiotics started. All the 41 cases had daily shower and local saline dressing of the surgical site.

\begin{tabular}{|c|c|c|c|}
\hline $\begin{array}{c}\text { Sl. } \\
\text { No. }\end{array}$ & $\begin{array}{c}\text { Operative } \\
\text { Procedures }\end{array}$ & $\begin{array}{c}\text { Number } \\
(\mathbf{N =} 650)\end{array}$ & $\begin{array}{c}\text { Developed SSI } \\
\text { (N= 41) }\end{array}$ \\
\hline 1. & Hernioplasty & $259(39.8 \%)$ & $18(43.9 \%)$ \\
\hline 2. & $\begin{array}{c}\text { Fibroadenoma } \\
\text { Excision }\end{array}$ & $114(17.5 \%)$ & $02(4.9 \%)$ \\
\hline 3. & Hydrocele & $103(15.8 \%)$ & $01(2.4 \%)$ \\
\hline 4. & $\begin{array}{c}\text { Ventral Hernia } \\
\text { Surgeries }\end{array}$ & $92(14.2 \%)$ & $17(41.5 \%)$ \\
\hline 5. & $\begin{array}{c}\text { Modified Radical } \\
\text { Mastectomy }\end{array}$ & $44(6.8 \%)$ & $03(7.3 \%)$ \\
\hline 6. & Thyroidectomy & $38(5.8 \%)$ & $0(0.0 \%)$ \\
\hline \multicolumn{3}{|c|}{ Table 1. Distribution of Surgeries and SSI } \\
\hline
\end{tabular}

Incidence of surgical site infection, $41 / 650=6.3 \%$

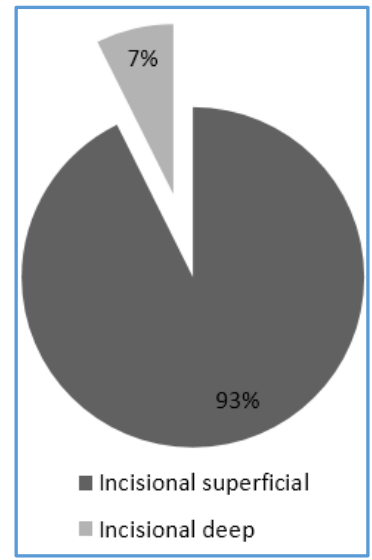

Figure 1. Type of SSI

\begin{tabular}{|c|c|c|c|c|c|c|c|c|}
\hline \multirow[b]{2}{*}{$\begin{array}{l}\dot{0} \\
z \\
\dot{\omega}\end{array}$} & \multirow[b]{2}{*}{ 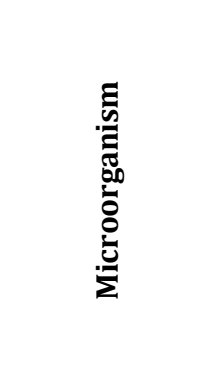 } & \multicolumn{7}{|c|}{$\begin{array}{l}\text { No. of Cases of SSI in } \\
\text { Various Surgeries }\end{array}$} \\
\hline & & 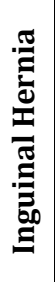 & 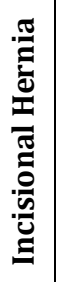 & 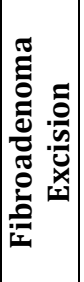 & 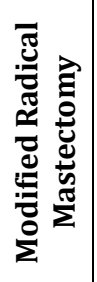 & 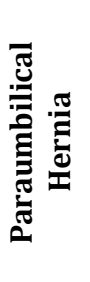 & 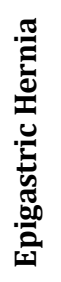 & 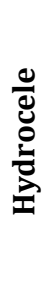 \\
\hline 1 & Staphylococcus & 10 & 10 & 2 & - & 1 & 1 & - \\
\hline 2 & $\begin{array}{l}\text { Coagulase -ve } \\
\text { Staphylococci }\end{array}$ & 6 & 2 & - & - & - & - & - \\
\hline 3 & Klebsiella & - & 2 & - & 1 & - & - & - \\
\hline 4 & Pseudomonas & 2 & 1 & - & - & - & - & - \\
\hline 5 & Proteus & - & - & - & 2 & & - & 1 \\
\hline & Total & 18 & 15 & 2 & 3 & 1 & 1 & 1 \\
\hline \multicolumn{9}{|c|}{ Table 2. No. of Cases of SSI in various Surgeries } \\
\hline
\end{tabular}

\begin{tabular}{|c|c|c|}
\hline $\begin{array}{c}\text { Socio-Demography } \\
\text { and Risk Factors }\end{array}$ & $\begin{array}{l}\text { Number } \\
(n=650)\end{array}$ & Percentage \\
\hline \multicolumn{3}{|c|}{$\begin{array}{c}\text { Age Group (Years) } \\
\end{array}$} \\
\hline$<30$ & 39 & 6.0 \\
\hline $31-40$ & 264 & 40.6 \\
\hline $41-50$ & 132 & 20.3 \\
\hline $51-60$ & 143 & 22.0 \\
\hline$>60$ & 72 & 11.1 \\
\hline \multicolumn{3}{|c|}{ Gender } \\
\hline Males & 339 & 52.2 \\
\hline Females & 311 & 47.8 \\
\hline \multicolumn{3}{|c|}{ Presence of Anaemia } \\
\hline Yes & 134 & 20.6 \\
\hline No & 516 & 79.4 \\
\hline \multicolumn{3}{|c|}{ Diabetes Mellitus } \\
\hline Yes & 63 & 9.6 \\
\hline No & 587 & 90.4 \\
\hline \multicolumn{3}{|c|}{ Overweight/ Obesity } \\
\hline Yes & 97 & 14.9 \\
\hline No & 553 & 85.1 \\
\hline \multicolumn{3}{|c|}{ Operating Time } \\
\hline$>90$ mins & 188 & 28.9 \\
\hline$<90$ mins & 462 & 71.1 \\
\hline
\end{tabular}




\begin{tabular}{|c|c|c|c|c|c|}
\hline \multirow{2}{*}{ Sl. No. } & \multirow{2}{*}{ Variables } & \multicolumn{2}{|c|}{ SSI } & \multirow{2}{*}{$\begin{array}{l}X 2 \text { value } \\
\text { (P value) }\end{array}$} & \multirow{2}{*}{$\begin{array}{c}\text { Odds Ratio } \\
\text { [95\% Confidence } \\
\text { Interval] }\end{array}$} \\
\hline & & $\begin{array}{c}\text { Present } \\
\text { N (\%) }\end{array}$ & $\begin{array}{c}\text { Absent } \\
\text { N (\%) }\end{array}$ & & \\
\hline \multirow{3}{*}{1.} & \multicolumn{3}{|c|}{ Age Group } & \multirow{3}{*}{$\begin{array}{c}0.022 \\
(0.886)\end{array}$} & \multirow{3}{*}{$0.95[0.48-1.85]$} \\
\hline & $\leq 50$ yrs & $27(6.2)$ & $408(93.8)$ & & \\
\hline & $>50$ yrs. & $14(6.5)$ & $201(93.5)$ & & \\
\hline \multirow{3}{*}{2.} & \multicolumn{3}{|c|}{ Sex } & \multirow{3}{*}{$\begin{array}{c}0.199 \\
(0.655)\end{array}$} & \multirow{3}{*}{$0.86[0.45-1.63]$} \\
\hline & Male & $20(5.9)$ & $319(94.1)$ & & \\
\hline & Female & $21(6.8)$ & $290(93.2)$ & & \\
\hline \multirow{3}{*}{3.} & \multicolumn{3}{|c|}{ Diabetes Mellitus } & \multirow{3}{*}{$\begin{array}{c}112.28 \\
\left(<0.0001^{*}\right)\end{array}$} & \multirow{3}{*}{$19.20[9.54-38.61]$} \\
\hline & Yes & $23(37.7)$ & $38(62.3)$ & & \\
\hline & No & $18(3.1)$ & $571(96.9)$ & & \\
\hline \multirow{3}{*}{4.} & & laemia & & \multirow{3}{*}{$\begin{array}{c}44.72 \\
\left(<0.0001^{*}\right)\end{array}$} & \multirow{3}{*}{$7.33[3.78-14.20]$} \\
\hline & Yes & $25(18.9)$ & $107(81.1)$ & & \\
\hline & No & $16(3.1)$ & $502(96.9)$ & & \\
\hline \multirow{3}{*}{5.} & \multicolumn{3}{|c|}{ Overweight/ Obesity } & \multirow{3}{*}{$\begin{array}{c}24.77 \\
\left(<0.0001^{*}\right)\end{array}$} & \multirow{3}{*}{$4.75[2.44-9.23]$} \\
\hline & Yes & $17(17.7)$ & $79(82.3)$ & & \\
\hline & No & $24(4.5)$ & $530(95.5)$ & & \\
\hline \multirow{3}{*}{6.} & & Iration of S & & \multirow{3}{*}{$\begin{array}{c}13.44 \\
\left(0.0002^{*}\right)\end{array}$} & \multirow{3}{*}{$3.14[1.65-5.96]$} \\
\hline & $>90$ mins & $22(11.8)$ & $164(88.2)$ & & \\
\hline & $<90$ mins & $19(4.1)$ & $445(95.9)$ & & \\
\hline \multicolumn{6}{|c|}{ Table 4. Statistical Significance of Risk Factors Studied } \\
\hline
\end{tabular}

$\left[{ }^{*} p<0.05\right.$ Statistically Significant $]$

\section{DISCUSSION}

In this study, the incidence rate of SSI was $6.2 \%$. This rate was very close to the rate of $1 \%-5 \%$ for clean surgeries in the Literature. Both male and female patients were almost equally affected by SSI (Males- 20, Females- 21 cases). Inguinal and Incisional Hernia surgeries contribute to majority of SSI with 33 cases out of 41 cases, which was $80.4 \%$ of the total cases. Out of that-

Incisional Hernia surgeries contributing- $36.5 \%$ of cases and

Inguinal Hernia surgeries contributing- $\quad 43.9 \%$ of cases as shown in table 2 .

Regarding signs and symptoms in SSI, 40 cases out of 41 cases had throbbing pain at surgical site $(97.5 \%$ of cases) as the main symptom and only 1 patient had swelling at the surgical site as main symptom. All the 41 cases had local tenderness and warmth at the surgical site. On removing 1 or 2 sutures, all 41 cases revealed purulent discharge. Regarding Time of Presentation, all the 41 cases in this study presented after $96 \mathrm{hrs}$. of surgery. In this study, incisional superficial type of SSI was more common with 38 cases out of 41 cases contributing to $92.7 \%$ cases and incisional deep type of SSI is seen only in 3 out of 41 cases contributing to $7.3 \%$ of cases as shown in Fig. 1.

\section{Microorganisms Studied from SSI}

- Staphylococcus aureus was responsible for majority of SSI affecting 24 out of 41 cases, which was $58.5 \%$ of total cases.

- $\quad$ Coagulase negative staphylococcus was responsible for 8 out of 41 cases, which was $19.5 \%$ of the total cases.

- Klebsiella, pseudomonas and proteus organisms were isolated in 3 cases, each out of 41 cases. In this study, staphylococcus aureus was seen to be the commonest organism responsible for SSI followed by coagulasenegative Staphylococcus as shown in Table 2. These data were same as in the literature that staphylococcus aureus and coagulase negative staphylococcus are the top 2 organisms responsible for SSI.

- $76.2 \%$ were due to Gram positive organism and rest $23.8 \%$ were due to Gram negative organisms.

Patient related risk factors such as (age, diabetes, anaemia, obesity (BMI > 30), duration of surgery) were included to study about their possible influence in SSI. Regarding risk factors and SSI, 15 cases out of 41 cases (36.5\%) did not have any risk factors and 26 cases out of 41 cases $(63.4 \%)$ had risk factors. Therefore, presence of risk factors probably increases the chance of SSI. $57.6 \%$ of 26 cases had $>2$ risk factors and $42.3 \%$ out of 26 cases had $\leq 2$ risk factors. Therefore, increase in number of risk factors probably further increases the chance of SSI.

It is evident from the study that diabetes, anaemia, obesity and duration of surgery have a statistically significant correlation with the development of surgical site infections with odds ratio of each being 19.20, 7.33, 4.75 and 3.14 respectively (Table 4). There was no significant difference in incidence among different gender and age group.

\section{CONCLUSION}

The following Conclusions were drawn out of this Observational Study on Clean General Operations

- The incidence rate of SSI is $6.2 \%$, which is close to the acceptable rate $(1 \%-5 \%)$ for clean surgeries.

- $\quad$ Risk factors- diabetes, anaemia, obesity and duration of surgery have a statistically significant correlation with the development of surgical site infections. Increase in number of risk factors further increases the chance of SSI.

- Incisional and Inguinal Hernia surgeries were commonly affected by SSI.

- Staphylococcus aureus was the commonest organism isolated. $76.2 \%$ were due to Gram positive organism and rest $23.8 \%$ due to Gram negative organisms. 


\section{REFERENCES}

[1] Leaper DJ, van Goor H, Reilly J, et al. Surgical site infection-a European perspective of incidence and economical burden. Int Wound J 2004;1(4):247-73.

[2] Altemeier WA. Sepsis in surgery. Presidential address. Arch Surg 1982;117(2):107-12.

[3] Jepsen OB, Larsen SO, Thomsen VF. Post-operative wound sepsis in general surgery. II. An assessment of factors influencing the frequency of wound sepsis. Acta Chir Scand Suppl 1969;396:80-90.
[4] Horan TC, Gaynes RP, Martone WJ, et al. CDC definitions of nosocomial surgical site infections, 1992: a modification of CDC definition of surgical wound infection. Infect Control Hosp Epidemiol 1992;13(10):606-8. 